\title{
Fernando GonzÁlez contra el PROyecto DE NACIÓN CONSERVADOR. APUNTES PARA UNA LECTURA CRÍTICA DE SU OBRA ${ }^{1}$
}

\author{
José Sebastián Castro Toro ${ }^{2}$ \\ Universidad de Antioquia
}

\begin{abstract}
Resumen: En este ensayo propongo una lectura comprensiva de la obra de Fernando González enmarcándola en en el contexto del proyecto nacional conservador enunciado en la Constitución de 1886 y desarrollado durante la Regeneración. Dentro de este marco exhibo los elementos de la obra con los que el autor construye un proyecto de nación que se opone en los puntos fundamentales al susodicho: al gramatismo mediante el lenguaje cotidiano y la lógica, al Estado confesional conservador mediante una religiosidad mística individualista, al apego al hispanismo mediante un ideal racial mestizo y al capitalismo colonial mediante una noción "comunista" de la propiedad.
\end{abstract}

Palabras clave: Proyecto de nación; Regeneración; Fernando González; lectura crítica.

Recibido: 19 de octubre de 2018.

Aprobado: 27 de noviembre de 2018.

Fernando GonZÁLEZ against THE CONSERVATIVE NATIONAL PROJECT. NOTES FOR A CRITIC LECTURE OF HIS WORK

\begin{abstract}
In this essay, I propose a understanding reading of Fernando González's work, framed in the context of the conservative national project, that was declared in the Constitution of 1886 and executed during the historical period known as "La Regeneración". In this regard, I show the elements with wich the author build a nation project that contradicts the above-mentioned in its key points: The grammatism through everyday language and logic, the conservative confessional state through an individualistic mystic religiosity, the attachment to hispanism through a mixed race ideal and to colonial capitalism by means of a "comunist" notion of property.
\end{abstract}

\footnotetext{
${ }^{1}$ Este artículo es un ejercicio personal derivado del ejercicio grupal del Grupo de Estudio Fernando González, activo entre el 2013 y el 2016.

${ }^{2}$ José Sebastián Castro es Filólogo hispanista. Sus áreas de investigación son: Literatura antioqueña, lingüística cognitiva y análisis del discurso. Correo electrónico: sebastian.gopernet@ gmail.com
} 
Keywords: Nation project; Regeneracion; Fernando González; critic lecture.

\section{La obra de Fernando González como proyecto de nación. Una lec- tura comprensiva}

La obra de Fernando González puede dividirse cronológicamente en tres etapas, la adolescente, la de madurez y la mística. En la primera podríamos ubicar la participación en Panida (1915), Una tesis (1919), Pensamientos de un viejo (1921) y materiales de la época que han sido publicados de manera póstuma. La segunda agruparía el grueso de su obra, desde Viaje a pie (1929) hasta El maestro de escuela (1942), pasando por los 17 números de la revista Antioquia que será editada por González entre 1936 y 1945, año a partir del cual dejará de publicar hasta 1959, cuando dé al público el Libro de los viajes o de las presencias y La tragicomedia del Padre Elías y Martina la velera (1962), etapa donde el elemento místico se vuelve central, sin perjuicio de razonamientos políticos, históricos, económicos y de actualidad.

La tesis que desarrollaré de manera sucinta en este ensayo plantea que al ubicar a Fernando González en el contexto histórico-político colombiano de finales del siglo XIX y principios del XX, puede encontrarse una continuidad a lo largo de su obra en tanto oposición ideológica y formal al proyecto de nación que gobernó el país desde la Constitución de 1886. Esta perspectiva evitaría en la lectura del autor el fanatismo y el desprecio simples con que ha sido leído en los últimos años por perspectivas cesgadas de influencia nadaísta, mediante la observación de propuestas ideológicas que pueden, o no, actualizarse a las necesidades de nuestros días; pero que muestran, en todo caso, una presencia coherente en toda la obra del filósofo, así como su papel en el pensamiento de la realidad histórica nacional y su entorpecido proceso de modernización.

Comenzaré observando que el estilo literario de González, marcado por un lenguaje desparpajado, coloquial y tendiente, a la fusión entre géneros "ensayo, novela, poesía, etc. se entiende por oposición" se explica por oposición a los postulados estéticos e intelectuales de quienes plantearon y consolidaron el proyecto de nación colombiano conservador en 1886, entre otros, Miguel Antonio Caro, Rafael Núñez 
y José Manuel Marroquín. Hay que notar que el patriciado en general se reunió en torno a un proyecto cultural de unificación de la nación, desplegado en en el campo científico mediante la Comisión Corográfica a mitad de siglo, que se encargó de realizar mapas y describir las diferentes regiones del país en busca de recursos explotables económicamente; y que esta tarea comenzada por la Comisión en el plano cartográfico y corográfico fue continuado por los escritores de artículos y cuadros de costumbres en periódicos como El Mosaico (Restrepo) para tratar la materia humana. Los gobernantes mencionados, que a su vez fueron intelectuales y autores literarios, se caracterizan por un apego a los moldes neoclásicos "en especial en el caso de Caro" y realistas, cuyas bases nacionales se instauran en el movimiento costumbrista, que pasará de cumplir una función enciclopédica y de dominio regional para configurar el inicio del canon literario colombiano en obras como el Museo de cuadros de costumbres (1866) y la primera Historia de la literatura colombiana (1867) dirigidas ambas por José María Vergara y Vergara. Así pues una revisión de los cuadros de costumbres permite determinar que las élites gobernantes, a pesar de ciertas divergencias políticas durante el desordenado siglo XIX, concordaron en un apego al purismo lingüístico y al trato del lenguaje popular como un simple objeto de estudio. Se disculpa Vergara (1866) en su Introducción, dirigiéndose al público peninsular, por usar los desvíos lingüísticos del pueblo. Este apego al purismo lingüístico como postulado formal y estético, digámoslo de una vez, se entiende como un apego a la herencia hispánica como definitorio de la nación, lingüística y racialmente y es incluso considerado en la época como un mérito necesario para acceder al poder, como sostiene el historiador Malcom Deas (1993). Y hay que observar que un postulado estético en manos de las élites gobernantes se convierte necesariamente en un postulado educativo. Esto se ratifica, entre otros sucesos, en la fundación de la Academia de la Lengua en el año 1871 por el mismo Caro, el compilador e historiador de la literatura Vergara y Vergara y José Manuel Marroquín; en la misma Constitución de 1886 que impone el proyecto nacional al que me refiero; y en el Concordato de 1887 celebrado entre la República de Colombia y la Iglesia donde, además de librarla de los impuestos y devolverle las 
tierras expropiadas durante los mandatos liberales, se le entrega a la Iglesia y a sus órdenes religiosas la educación del pueblo colombiano. Y así tenemos a Fernando González, el irreverente discípulo de los jesuitas, nacido en 1895, una década después del establecimiento de la regeneración. Y de aquí la importancia de comenzar el comentario sobre la oposición a tal proyecto nacional con el elemento estilístico y lingüístico.

González hace parte de la camada del nuevo siglo que, aprendiendo de Rubén Darío y la cultura intelectual francesa, como puede observarse en Panida, interiorizó el modernismo. Esto se ve en el estilo del autor en la fragmentariedad y la tendencia al aforismo y la sentencia que recuerda al Zaratustra. En la época de madurez, donde se desarrolla centralmente la oposición aquí detallada, su estilo también madura. Manteniendo la fragmentariedad, e incluso haciendo un uso literario y reflexivo de la despersonalización, su escritura se asemeja conscientemente al discurso oral. Trata de escribir lo más coloquialmente posible, echando mano de regionalismos y maldiciones que causarán escándalo en la censura nacional, llevando a la conocida prohibición de varios de sus libros. Rechaza de esta manera la hipercorreción y la subyugación académica. No inicia nunca relaciones con el gramatismo de los Caro, los Cuervo, los Vergara, los Marroquín, etc. Introduce las palabras que usa la gente del común en su territorio pero no lo hace pidiendo permiso a la Academia de la Lengua ni avergonzado de la degeneración del español, como es el referido caso de Vergara en el Museo de cuadros de costumbres (Vergara y Vergara). Rechaza el vanidoso moralismo en la lengua. Si la vida colombiana es inmoral, el lenguaje que hable sobre la vida debe ser inmoral. González trata de acercarse a los usuarios de la lengua ${ }^{3}$. Para ilustrar esto es célebre la carta que envía a su editor dispuesto a retirar de la imprenta El remordimiento (1935) por la censura de su lenguaje:

No se publicará el libro, pero vas a ver cómo tengo razón. Si la Toní, si la vida no es propia para Colombia, si no tiene la belleza legal colombiana, ¡mejor! Si yo escribiera libros aprobados aquí, no valdría nada, sería un Laureano Gómez [...] ¿Cómo te atreviste a poner "calzones" de Toní, en vez de "calzoncitos"? La muchacha tiene "calzoncitos",

\footnotetext{
${ }^{3}$ Esto no quiere decir, por supuesto, que todo su lenguaje sea coloquialista. Abundan en sus obras las citas en latín, francés e italiano y en ocasiones en inglés y alemán.
} 
o sea, pequeños, limpios [...] Pusiste "prendas de su feminidad íntima", en lugar de "ropitas de Toní". "Prendas" es como dicen los padres Ochoa y Mejía, curas de Envigado, en el púlpito, o sea, pornografía, hipocresía, vergüenza, pecado (González, "El remordimiento" 161—62).

González busca, pues, romper con el moralismo que rige al lenguaje, romper con el lazo que une servilmente a Colombia con España. Realizar la tan sonada independencia intelectual que ha sido tan mal entendida y tan poco practicada. En este punto no sigue el ejemplo del ilustre Andrés Bello y algunos de los filólogos y gramatistas neogranadinos, realizando el estudio sistemático de la lengua americana como variante, sino que, más bien, sigue la línea comenzada por Simón Rodríguez, quien, como señala Rama (1998) “propuso, no un arte de escribir, sino un arte de pensar, y a éste supeditó la escritura" (66) . Así, a ambos autores, y es González admirador de Rodríguez como se lee en Mi Simón Bolívar, les preocupa dar a las ideas su expresión propia como enseñanza fundamental de la infancia, y como principio para la escritura. Esto explica el desprecio profesado al gramatismo por parte de González y su cercanía con la lógica, en tanto instrumento para valorar el pensamiento y para construir métodos, a lo cual fue aficionado siempre. Por su contención metódica admiró siempre a los ejercitantes jesuitas y, a pesar de alejarse de ellos para seguir su camino y para elevar la crítica a la colombia conservadora, concuerda tanto con los jesuitas como con Rodríguez en la importancia de la educación en la lógica para la formación. Esto queda claramente sentado en Los Negroides:

Lo esencial en los programas de la escuela, es la lógica. Toda ciencia tiene un método, un ritmo; todo hombre tiene su método y su ritmo; he ahí cuál debe ser la base de las escuelas. Programa que no comporte curso de lógica en cada año de estudios, es fracaso (Los negroides).

La lógica es, pues, el instrumento para cogerle el ritmo a la vida y la educación se trata de vivir, no de escribir conforme a la academia. Se trata de oponer la liberación mediante el pensamiento a la dominación por las formas. De contrariar una de las bases del proyecto de nación de los próceres de la cultura. 
Pero esta oposición de corte estilístico en la etapa de madurez, el apego a la lógica y el lenguaje cotidiano, no constituye, por supuesto, algo especial. Pasaré ahora a mostrar la oposición ideológica que puede encontrarse en la obra de Fernando González, resumible en dos elementos: la relación iglesia-Estado, la concepción del pueblo y su identidad y la noción de la propiedad. Para esto ahondaré un poco en el contexto histórico y la composición de las mentadas élites.

Disuelta la República de Colombia, tras múltiples esciciones del territorio bolivariano, aparece en 1832 la República de la Nueva Granada, la actual República de Colombia desde 1886. Sus élites gobernantes, conformadas fundamentalmente por descendientes de la burocracia virreinal, hijos de enconmenderos y latifundistas surgidos con las reformas agrarias bolivarianas (Romero), se enfrentaron a partir de entonces por qué tanto aplicar las reformas estructurales que el capitalismo moderno exigía para ingresar en el sistema de mercado mudial y qué tanto apegarse al sistema colonial basado en el latifundismo que les favorecía económicamente, un sistema de corte feudal, pero capitalista, llamado por Bagú capitalismo colonial. Hay que observar, en vista de lo anterior, que el pleito fundamental será siempre el del tipo de tenencia de la tierra, el del tipo de propiedad, pues el capitalismo moderno implica un régimen de tenencia mixto con tendencia a la pequeña propiedad que va en contravía de las grandes propiedades y, por tanto, del uso de mano esclava. Es por esto que la Colombia de Fernando González, aún la de hoy, será un país que cumple la observación de Bagú: "un país políticamente independiente puede sin embargo padecer de una economía colonial o semicolonial" (104), y la perpetuación de un país estructuralmente semicolonial será una de las bases económicas del Estado colombiano.

Se inaugura pues, también, una tensión entre las formas políticas y sus implicaciones económicas, ocultando las segundas bajo las primeras. Gran parte de las guerras civiles que tendrán lugar durante el siglo XIX en nuestro país y continente girarán alrededor de la oposición centralismo/federalismo, lo cual dividirá al patriciado embarcándose en recurrentes y sangrientas pugnas. Otro de los puntos que fracturará el patriciado será uno que, usualmente abordado desde la filosofía y 
formalidad política, tiene sin embargo un obvio trasfondo económico, es el de la relación entre el Estado y las instituciones religiosas, en nuestro caso particular, entre el Estado y la Iglesia Católica de Roma. Esta unión, heredada del gobierno colonial, y la idea liberal de la independencia estatal será, quizás, el punto de mayor desavenencia en nuestra historia y se resolverá a finales de siglo, como ya se mencionó, con el Concordato de 1887.

Si se estudia el enfrentamiento de los patricios a través del Partido Liberal y el Partido Conservador, surgidos a mediados de siglo, se observa que la discusión por un estado no confesional, es el único punto real de divergencia. Al revisar los textos fundacionales de cada partido y su evolución a lo largo del siglo XIX, (siendo el primero para el partido Liberal La razón de mi voto de Ezequiel Rojas de 1847 y para el Conservador el programa de 1849 escrito e ideado por Mariano Ospina Rodríguez y José Eusebio Caro) uno puede darse cuenta de que ambos partidos concuerdan, de la mano de hombres como José María Samper en el programa conservador de 1870, en la visión progresista de la sociedad, ${ }^{4}$ entendiendo progreso en términos de infraestructura, la construcción de carreteras y otras mejores materiales. Además, ambos partidos fueron en diferentes momentos centralistas y federalistas, por lo cual es inútil pensar este elemento como su punto central de división. Mariano Ospina Rodríguez, fundador del Partido Conservador, convirtió al país en la Confederación Granadina. Y en cualquier caso, ambos partidos, en la práctica, llevaron a cabo a medias la implementación de las reformas económicas, que poco se nombran en muchos de los documentos partidistas liberales del siglo XIX. Por tanto, reitero, la relación estado-iglesia fue para los partidos la cuestión central.

Esta omisión del asunto económico solo tiene excepción en el artículo de Manuel Murillo Toro publicado por en 1853 en el periódico el Neogranadino y que se considera como programa del Partido

${ }^{4}$ Este panorama es un resumen realizado a partir de la lectura de los programas del Partido Liberal y el Partido Conservador desde su fundación hasta el final del siglo XIX, encontrados en Jordán Florez y Directorio Nacional Conservador. Un punto a recalcar es que el programa publicado en 1881 con Núñez como presidente, será el último programa oficial hasta el arribo de la Constitución de 1886, que podriá considerarse en sí misma un programa cosnservador. A partir de aquí el conservadurismo no actualizará su programa hasta la década del 30 del siglo XX, cuando se vea amenazado por el ascenso liberal. Esto sustenta la visión del conservadurismo como un movimiento fundamentalmente reaccionario. 
Liberal. Allí, Murillo afirma que todas las pugnas de los conservadores y los liberales son bagatelas en tanto ninguna interviene el punto central. ¿Cuál?, el de la tierra, el de la propiedad. ¿De qué sirve la declaración del voto universal si el campesino no tiene independencia económica y por tanto depende de la opinión y el poder del gamonal y del atrio de la iglesia? Este hombre, Manuel Murillo Toro, expone una de las más contundentes y viejas denuncias de nuestro fracaso como república moderna en tanto denuncia que el general José Hilario López, presidente liberal, a pesar de haber dado importantes pasos para entrar a un capitalismo moderno, como la emancipación de los esclavos, la desamortización de manos muertas, la expulsión de los jesuitas y la progresiva secularización del estado, se detuvo en el punto vital de la reforma agraria. Teniendo estos elementos delineados, entremos en materia sobre cómo se opone González al qué del proyecto nacional conservador de la Regeneración.

Como hemos visto, con Viaje a Pie, libro polémicamente célebre a causa de su prohibición arzobispal, inicia la etapa madura del autor. Es esta etapa la que articula el proyecto de nación de Fernando González y su expreso deseo de oposición puede encontrarse tanto en la dedicatoria "al general Tomás Cipriano de Mosquera, mi conciudadano" (González, Viaje a pie 27) como en su finalidad, que se describe en el Epílogo:

Tú, Margarita, que sabes el intenso amor del autor por su tierra colombiana, por el aire colombiano, por el Simón Bolívar solitario de Santa Marta, por el mar territorial, eres la única que puede entender la finalidad de este libro: describirle a la juventud la Colombia conservadora de Rafael Núñez; hacer algo para que aparezca el hombre echado para adelante que azotará a los mercaderes. Para ti este libro; tú sabes qué piensa el autor de Nuestro Señor Jesucristo (246).

Viaje a pie es contemporáneo de un cambio de régimen en el país. Sucesos internos como la masacre de las bananeras en 1928, y externos como la crisis económica mundial que llevó a la crisis del rubro central de la economía colombiana del momento, el café, ponen en jaque la hegemonía conservadora y en 1930 el liberalismo asciende al poder. Es en este contexto que Fernando González va a hacer algo para que 
aparezcan los hombres echados pa'lante que puedan dejar atrás el peso del proyecto nacional regeneracionista delineado, que para Fernando se encarna en Núñez, como vimos en el Epílogo.

Adquirida una conciencia del devenir histórico colombiano, González actúa desde dos frentes en tanto desarrollo de ideas; desde su individualismo místico y desde su idea del mestizaje. El primero es la gran constante a lo largo de toda su obra, pues no es en vano, aunque muchos lo quieran obviar, que Viaje a pie cierre haciendo alusión a su Señor Jesucristo; y la segunda es desarrollada concretamente en $\mathrm{Mi}$ Simón Bolivar y en Los Negroides. Esto, por supuesto, es tan amplio como complejo, pero trataré de ser lo más fiel y concreto posible para mostrar cómo estas disquisiciones, que tienen un evidente carácter metafísico y ético, confunden sus fines teóricos con los intereses políticos del autor y con las necesidades del contexto de la época.

Para muchos lo fundamental de Fernando González, en tanto transversal, es su visión mística y religiosa de la vida íntima. Dada su crianza y sus lecturas de Nietzche, Voltaire, Schopenheur, entre otros, González encarna un "entre" cultural. Se encuentra inmerso en los procesos de secularización propios de la modernidad, como señalaría Gutiérrez Girardot $(1983)^{5}$, pero habita un país sumamente católico y su crianza por los racionales jesuitas le dejará una mella imborrable. Por esta situación intermedia en el proceso de secularización, Fernando se la pasa bregando con Dios. Y esa brega lo llevará a desarrollar toda una teoría del viaje interno para alcanzar a Dios que es la intimidad, es decir, que está en él. Esto puede comprenderse como una religiosidad individualista que colabora con la separación entre el Estado y la Iglesia.

Como místico, su relación con Dios es íntima. En Los Negroides (1936) Fernando expresa que Cristo es inagotable a pesar de sus interpretaciones superficiales y que "el verdadero cristianismo es esotérico" (Los negroides), es decir, interior, íntimo, quizás oculto. Por eso su relación con el clero colombiano es conflictiva, porque su visión de la religión, que empaña todo lo que escribe, se acerca más a la religión reformista, protestante, que a la católica colombiana o a cualquiera de orden institucional con intereses en la propiedad de la

${ }^{5}$ Entiendo por secularización, con Gutierrez "un proceso por el cual partes de la sociedad y trozos de la cultura se liberan del dominio de las instituciones y símbolos religiosos" (35). 


\section{José Sebastián Castro Toro}

tierra y en el desenvolvimiento político del país. ¿Cómo más combatir un proyecto de nación que involucra el cristianismo que proponiendo una evolución individualista de este y la consecuente liberalización del estado? La modernidad implica la secularización del estado y a esto sirve el misticismo de González y afirmaciones como "el verdadero Cristo no era de rebaño". Se trata de teología contra teología, una salida que es fiel a la formación del autor.

Esta salida, por supuesto, puede no parecer completamente satisfactoria en tanto solución de la secularización del Estado. Sin embargo, habría que considerar que la cercanía de este misticismo con el protestantismo, de ser realmente aplicable y de haber sido promovido por González u otros en función de gobierno, hubiera representado a mediados del siglo XX colombiano una salida al extremismo religioso que recrudeció la Violencia partidista.

Ahora bien, si los patricios buscaban fortalecer sus lazos con España y se reivindicaban a sí mismos mediante la idealización de la raza blanca como seña española y característica que los diferenciaba del vulgo: mestizos, mulatos, indios y negros; Fernando defendió siempre la idea de un mestizaje entre las tres razas que a su juicio eran las raíces de Colombia, sus raíces. En lo cual sigue claramente el proyecto delineado por Simón Bolívar en el Discurso de angostura. El ideal que debía buscarse, el del Gran Mulato, tenía que ser asumido por el Estado mediante la creación de institutos que regularan la mezcla de las razas. Esto con el fin de conseguir la raza suramericana que sería el punto supremo del hombre, el hombre con conciencia cósmica al reunir todos los instintos humanos. Raza de la que Bolívar había sido muestra.

Esta idea racial se complementa con la idea, propia de la malinterpretación de la evolución biológica que infestó la historia, la sociología, la economía y la filosofía, de que los pueblos, más o menos equivalentes a las razas, degeneraban. Y, por tanto, mediante el mestizaje, para la estabilización del pueblo —nótese que es una oposición diametral en los proyectos, pues en ambos se mantiene la idea de que la identidad del pueblo depende de la raza - debían curarse vicios de la comunidad. Dado que los individuos heredaban estos vicios, la solución racial es acompañada en la obra de González por una 
reflexión sobre la personalidad y cómo solucionar en ella los complejos de inferioridad propios de un pueblo sometido:

Yo, señores, fui el niño más suramericano. Crecí con los jesuitas; fui encarnación de inhibiciones y embolias; no fui nadie; vivía de lo ajeno: vivía con los Reverendos Padres... De ahí que la protesta naciera en mí y que llegara a ser el predicador de la personalidad (González, Los negroides).

En resumen, en vez de buscar en las raíces hispánicas la identidad de la nación y los ideales de la misma, González propone una mezcla de los elementos raciales presentes en el territorio colombiano con miras a establecer un tipo nacional, proyecto eugenésico que debe ser asumido por el Estado.

Pero había señalado también que las discusiones políticas e incluso las proyecciones sobre el pueblo eran realmente superficiales ante lo que realmente defendía el proyecto de los patricios, y no solo conservadores, esto es, sus derechos coloniales sobre la tierra. ¿Aborda el autor este punto? Como hombre político no solo lo aborda teóricamente, como veremos a continuación, sino que intentó la vía del gobierno. A este fracaso valdría la pena dedicarle algunas palabras. Varias columnas publicadas en El Diario Nacional entre 1936 y 1937 , publicadas póstumamente como Nociones de izquierdismo, que fueron la base ideológica de La Izquierda Nacional, LAIN, partido fundado por González, y otros intelectuales de la región, que lanzó listas propias para la Asamblea Departamental y el Concejo de Medellín, con resultados no muy alentadores aparte del puesto para González como asesor legal en la oficina de Valorización Municipal que devendrá en la publicación del Estatuto de Valorización de 1942. El partido decayó en 1945, ante la confluencia del liberalismo social en torno a Gaitán, y desapareció luego del asesinato del mismo, el consecuente desenfreno de La Violencia y la persecución estatal de la oposición al gobierno conservador que llevó a unos al exilio, a otros a la reclusión, y a González al silencio (Escobar) ${ }^{6}$.

\footnotetext{
${ }^{6}$ Aquí sigo a Miguel Escobar, pero para la reconstrucción biográfica expuesta en este trabajo se utilizan primodialmente las fuentes primarias, dado que la obra de González es fundamentalmente autobiográfica. Sin embargo, contribuyen también, y por tanto deben mencionarse, dos de los trabajos más juiciosos sobre el autor que se han realizado, Para leer a Fernando González del
} 


\section{José Sebastián Castro Toro}

El razonamiento de González sobre la propiedad es uno de los que más evoluciona a lo largo de su obra. Pasa de dar por hecho cualquier tipo de propiedad privada en Una Tesis, a la concepción de propiedad común y conciencia comunista que desarrolla en Nociones de izquierdismo. Este punto es de suma importancia y dicha evolución se explica, en el marco de este trabajo, como un desarrollo comprensible al analizar las coyunturas que afrontó el país durante la primera mitad del siglo XX. En los años 30, Alfonso López Pumarejo, encabezando el liberalismo, trata de implementar unas modificaciones a la tenencia de tierra y el manejo de la propiedad que se formalizarán en la ley 200 de 1936 y que tenían una vocación social, como el momento histórico de capitalismo lo requería. Esto, sin embargo, no puede confundirse con una reforma agraria, aunque pudo haber sido un comienzo. La aplicación de dicho proyecto será obviado por el sucesor de López en 1936: Eduardo Santos. Al respecto de tal elección y la coyuntura histórica que ponía en tela de juicio el cumplimiento de la función histórica del liberalismo, dice González en las Nociones:

Porque en realidad, hay que repetirlo, la candidatura de Eduardo Santos es reaccionaria. Digan lo que quieran, fue iniciada y es sostenida por los poseedores satisfechos, pero que se sienten amenazados por algunos proyectos de modificación de nuestras instituciones coloniales $[\ldots]$

En efecto, como está escrito, Santos decretó la llamada "gran pausa", que echó atrás gran parte de lo intentado por López en temas de reformas económicas. Ante ese panorama, y ya con la presencia de Gaitán, escribe González en 1945:

Gaitán anda triunfalmente por el departamento de Caldas, única tierra colombiana en donde hay campesinos conscientes [...] Apenas principie nuestro gobierno, cesará la herencia económica. El derecho de propiedad individual es un sueño. Lo único real es uso, consumo y habitación. Y estos tres derechos se garantizarán. ¿Para quién serán las riquezas? Para el Hombre. ¿Cuál será la mejor riqueza? El hombre. No se trata de quitarte lo tuyo, sino de que todo sea para todos. Cierra

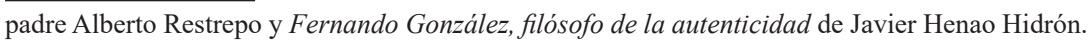


los ojos, recógete y verás cómo el pueblo ha sido traicionado. Un gran pueblo ha sido traicionado por el Gobierno que estableció hace quince años (González, Revista Antioquia 16)

La reflexión de González sobre la tenencia de la tierra, como se lee, tiende a la repartición y la propiedad común. Sin embargo, como más que economista y estadista González es filósofo, su reflexión sobre la propiedad se rastrea a través de la idea de que "la evolución de la conciencia humana puede considerarse como la misma de la noción de propiedad" (Nociones de izquierdismo), con lo cual relaciona, para efectos críticos, el estado de la propiedad en una comunidad, nación o persona a partir de qué concibe como propio. Esta idea es desarollada desde Mi Simón Bolivar bajo el concepto de concienciómetro. No obstante, para los fines de este ensayo, basta enfatizar en que la noción de la propiedad de González es evolutiva y tiende a la universalidad, es decir, a la propiedad común o disolución de la propiedad en la comunidad, así como a la eliminación del derecho hereditario sobre la propiedad de la tierra, operando entonces con un concepto de comunismo bastante heterodoxo: "no hay oposición entre yo y tú, mío y tuyo [...] comunismo, como es obvio, no se impone sino que es perfección a que se llega mediante disciplinas. Es un estado de conciencia que tuvieran Jesucristo, Buda, Sócrates y Nietzsche", que, en todo caso, se opone a la noción de propiedad privada y privilegiada de la Regeneración enfocada en el latifundismo.

\section{Conclusiones: apuntes para una valoración crítica de la obra de Fernando González}

En conclusión, si se aceptan como elementos de un proyecto de nación conservador colombiano el gramaticalismo (formalismo), clericalismo, purismo racial blanco y perpetuación de los derechos de propiedad coloniales, y se aceptan como rasgos de un proyecto de nación disidente los señalados en la obra de Fernando González, puede usarse esta tesis para realizar lecturas transversales y comprensivas de las obras del autor, trascendiendo bajo un criterio evolutivo sus contradicciones. Esto porque los elementos desarrollados en este ensayo son problemas continuos del autor. El estilo tiene cambios, 
primordialmente en la etapa adolescente, pero se mantiene siempre opuesto al academicismo y el gramaticalismo. El elemento místico, que en la adolescencia está permeado por una vena escéptica, se articula en la madurez con la política y se hace central en la vejez. La reflexión sobre la propiedad se profundiza desde la adolescencia, en Una tesis, de espíritu fundamentalmente liberal, a Nociones de izquierdismo, donde el autor plantea su noción de una propiedad comunista. Y, finalmente, el elemento de la raza mestiza, si bien aparece principalmente en la época de madurez, al estar articulado con la reflexión sobre la búsqueda de personalidades fuertes a través de disciplina y método, también puede considerarse ubicuo.

Así pues, sostenida la tesis, hay que advertir que bajo esta línea puede comprenderse la obra de González como un trabajo intelectual por generar valores que se opusieran a los intereses de "los poseedores satisfechos" como él los llamó, y que, por tanto, sirvieran para generar un cambio en la nación colombiana.

Esta lectura comprensiva podría facilitar una valoración crítica del autor donde se pongan en tela de juicio la validez y coherencia de los elementos que consideraba adecuados para el país y ver si tienen algún valor en el presente, de una manera racional y directa. Una crítica que se pregunte si su racismo, su misticismo, su primitiva visión del erotismo y de la mujer, el tipo de liberalismo de sus primeras obras, la contradicción no sintetizada; para nombrar algunos de los asuntos más problemáticos de la obra de González, son salvables y si su proyecto de nación, en el cual su noción amplia de la propiedad no da luces sobre la manera de solucionar la cuestión agraria, tiene alguna relevancia en nuestros días. Es indudable, en todo caso, el auténtico intento del autor por aportar al progreso del país y su modernización, así como su trabajo constante en el pensamiento de la cuestión colombiana. 


\section{Referencias}

Bagú, Sergio. Economía de la sociedad colonial. Ensayo de historia comparada de América Latina. Editorial Grijalbo, S.A, 1992. Impreso.

Directorio Nacional Conservador. Los programas conservadores de 1849 a 1949. Directorio Nacional Conservador, 1952.

Escobar, Miguel. "Crónica a manera de prólogo". Arengas políticas, editado por Otraparte, http://www.otraparte.org/ideas/1945-arengas.html, 2012. Digital.

González Ochoa, Fernando. «El Remordimiento.» González, Fernando. Salomé; El remordimiento. Fondo Editorial Universidad EAFIT, 2008. 159362. Impreso.

—. Los negroides. 1936, http://www.otraparte.org/fernando-gonzalez/ ideas/1936-negroides.html. Digital.

_. Nociones de izquierdismo. 1937, http://www.otraparte.org/fernando-gonzalez/ideas/1936-nociones.html. Digital.

_. Revista Antioquia 16. 1945, http:/www.otraparte.org/fernando-gonzalez/ ideas/antioquia/antioquia-16.html. Digital.

—. Viaje a pie. 8va ed. Fondo Editorial Universidad Eafit, 2010. Impreso.

Gutierrez, Rafael. "Introducción: los problemas de la modernidad". Modernisno. Supuestos históricos y culturales. Fondo de Cultura Económica, 1983, pp. 22-37. Impreso.

Jordán Florez, Fernando. Antología del pensamiento y programas del partido liberal 1820-2000. Tomo I. Primera ed, Partido LIberal Colombiano, 2000. Impreso.

Rama, Angel. La ciudad letrada. Arca, 1998. Impreso.

Restrepo, Andrés Gordillo. "El Mosaico (1858-1872): nacionalismo, elites y cultura en la segunda mitad del siglo XIX". Fronteras de la Historia, núm. 8, 2003, pp. 19-63. Impreso.

Romero, José Luis. "Las Ciudades Patricias". Latinoamerica: las ciudades y las ideas, Cuarta edi, Siglo XXI, 1986, pp. 173-246. Impreso.

Vergara y Vergara, José María. "Prólogo". Museo de cuadros de costumbres variedade y viajes, vol. 1, Biblioteca Banco Popular, 1973, pp. 7-11. Impreso. 